\title{
The role of cumulative physical work load in lumbar spine disease: risk factors for lumbar osteochondrosis and spondylosis associated with chronic complaints
}

\author{
A Seidler, U Bolm-Audorff, H Heiskel, N Henkel, B Roth-Küver, U Kaiser, R Bickeböller, \\ W J Willingstorfer, W Beck, G Elsner
}

\begin{abstract}
\end{abstract}
Objectives-To investigate the relation with a case-control study between symptomatic osteochondrosis or spondylosis of the lumbar spine and cumulative occupational exposure to lifting or carrying and to working postures with extreme forward bending.

Methods-From two practices and four clinics were recruited 229 male patients with radiographically confirmed osteochondrosis or spondylosis of the lumbar spine associated with chronic complaints. Of these 135 had additionally had acute lumbar disc herniation. A total of 197 control subjects was recruited: 107 subjects with anamnestic exclusion of lumbar spine disease were drawn as a random population control group and 90 patients admitted to hospital for urolithiasis who had no osteochondrosis or spondylosis of the lumbar spine radiographically were recruited as a hospital based control group. Data were gathered in a structured personal interview and analysed using region, nationality, and other diseases affecting the lumbar spine. To calculate cumulative forces to the lumbar spine over the entire working life, the MainzDortmund dose model (MDD), which is based on an overproportional weighting of the lumbar disc compression force relative to the respective duration of the lifting process was applied with modifications: any objects weighing $\geqslant 5 \mathrm{~kg}$ were included in the calculation and no minimum daily exposure limits were established. Calculation of forces to the lumbar spine was based on self reported estimates of occupational lifting, trunk flexion, and duration.

Results-For a lumbar spine dose $>9 \times 10^{6}$ Nh (Newton $\times$ hours), the risk of having radiographically confirmed osteochondrosis or spondylosis of the lumbar spine as measured by the odds ratio (OR) was 8.5 (95\% confidence interval $(95 \% \mathrm{CI}) 4.1$ to 17.5) compared with subjects with a load of $0 \mathrm{Nh}$. To avoid differential bias, forces to the lumbar spine were also calculated on the basis of an internal job exposure matrix based on the control subjects' exposure assessments for their respective job groups. Although ORs were lower with this approach, they remained significant. Conclusions-The calculation of the sum of forces to the lumbar spine is a useful tool for risk assessment for symptomatic osteochondrosis or spondylosis of the lumbar spine. The results suggest that cumulative occupational exposure to lifting or carrying and extreme forward bending increases the risk for developing symptomatic osteochondrosis or spondylosis of the lumbar spine. (Occup Environ Med 2001;58:735-746)

Keywords: case-control study; physical work load; lumbar osteochondrosis; lumbar spondylosis

The evidence for an association between low back pain and physical workplace factorssuch as lifting and carrying of heavy loads, awkward postures, and whole body vibration is strong, as summarised in recent detailed

Main messages

- In a case-control study, osteochondrosis or spondylosis associated with chronic complaints was found to be related to lifting or carrying of weights and working postures with extreme forward bending.

- We found a clear dose-response relation between cumulative physical work load and the diagnosis of symptomatic osteochondrosis or spondylosis of the lumbar spine with large odds ratios for high exposure categories.

Policy implications

- The calculation of the sum of force on the lumbar spine is a useful tool for risk assessment of symptomatic osteochondrosis or spondylosis of the lumbar spine; this tool might be applied in compensation practice as well as for preventive purposes.

- Prevention of lumbar spine disease should take into account the possibility that even moderate force on the lumbar spine might contribute to the development of lumbar spine disease in cases of long term exposure. 
reviews of epidemiological studies. ${ }^{1-3}$ Low back pain may have multiple origins, including muscle strain as probably the most common cause, and disc pressure on the annulus fibrosus, vertebral end plate, or nerve roots. As Bernard pointed out, ${ }^{1}$ subjectively defined health outcomes must be included in any consideration of work related back disorders because they comprise such a large subset of the total. On the other hand, combining different disease entities in epidemiological studies might lead to difficulties in identifying potential aetiological factors. Furthermore, the current discussion in several European countries about the formal recognition that occupational factors play a part in the development of diseases of the lumbar spine would benefit from more specifically defined health outcomes, as far as possible using objective medical criteria. Since 1993 diseases of the lumbar spine related to carrying or lifting of heavy loads or to working postures with extreme forward bending can be compensated as occupational diseases in Germany. Thus osteochondrosis or spondylosis of the lumbar spine associated with chronic complaints as well as lumbar disc herniation may be recognised as occupationally acquired. In practice, recognition rates are currently very low, mainly due to the imprecise definition of health outcomes as well as to the imprecisely defined - and controversially discussedamount of physical work load required for a given outcome to occur.

Radiographically confirmed osteochondrosis or spondylosis of the lumbar spine constitute important pathological conditions potentially causing low back pain. Many studies have provided evidence that osteochondrosis or spondylosis of the lumbar spine are associated with an increased risk of low back pain ${ }^{4-11}$ or sciatic pain, ${ }^{12}$ only few studies failed to confirm this association. ${ }^{13}{ }^{14} \mathrm{~A}$ recently published study ${ }^{15}$ using immunohistochemical techniques suggested an important role for nerve growth into the intervertebral disc in the pathogenesis of chronic back pain.

Most epidemiological studies on the relation between occupational work load and radiographically detectable spine alterations were carried out more than 10 years ago, when radiographic examinations of healthy people for research purposes met with little ethical disapproval. These studies, mostly cross sectional, ${ }^{4} 71216-21$ showed a positive association between working in occupations with heavy physical work load-for example, miners, dockers, concrete reinforcement workersand the prevalence of osteochondrosis or spondylosis of the lumbar spine. However, these studies have certain limitations: exposure assessment is usually crude; cross sectional studies tend to be prone to substantial selection bias; competing risks are incompletely considered; the adequate choice of comparison groups is sometimes questionable; and only the most recently held occupation is considered.

Therefore, further research was required to better define the relation between work load and osteochondrosis or spondylosis of the lumbar spine associated with chronic complaints (symptomatic osteochondrosis or spondylosis). The aim of the present casecontrol study was to examine the relation between symptomatic osteochondrosis or spondylosis and cumulative exposure of the lumbar spine to lifting or carrying and working postures with extreme forward bending.

\section{Subjects and methods}

STUDY POPULATION

Our study was performed in the city of Frankfurt am Main and surrounding area. Patients with osteochondrosis or spondylosis of the lumbar spine were recruited in two orthopaedic practices, in one orthopaedic clinic, and three neurosurgical clinics in Frankfurt am Main and the neighbouring city of Offenbach. Practices and clinics from which cases were drawn were not specialised in workers' compensation cases or certain industries. Participating physicians were asked to identify all male patients between 25 and 65 years with osteochondrosis or spondylosis of the lumbar spine associated with chronic complaints (low back pain, sciatica) as well as all patients who had had acute lumbar disc herniation. These patients with lumbar disc herniation were recruited for a parallel study about risk factors for lumbar disc herniation; patients who had osteochondrosis or spondylosis as well as lumbar disc herniation were included in both studies. Participating physicians were instructed to recruit only patients whose initial diagnosis of lumbar spine disease had not been made more than 10 years earlier. However, as recruiting physicians often had not treated the patients before the current episode of their disease, a precise assessment of the date of initial diagnosis was not always possible. Therefore, in those patients who recalled an earlier date for acute lumbar disc herniation than the physician in attendance, this was taken as the date of diagnosis of the lumbar spine disease. We did not exclude patients whose date of diagnosis was, as a consequence of this procedure, more than 10 years ago $(n=30)$.

Of 549 eligible patients, 437 agreed to participate $(80 \%)$. Patients with Bechterew's disease, fractures of the spine, malignancies involving the spine, and poliomyelitis were excluded from the study (fig 1). Those patients who did not report having had low back pain for more than 7 days during the preceding 12 months (patients without chronic complaints; fig 1) were also excluded at this point. $x$ Ray films of the lumbar spine were reassessed by one reference radiologist (WJW) blinded to the case-control status (separately for each disc and vertebral body) according to the following criteria (22 23 ; with modifications).

(0) Normal=no narrowing of intervertebral disc, no osteophytes.

(1) Minimal osteochondrosis or spondylosis= minimal narrowing of intervertebral disc or minor osteophytes ( $\leqslant 2 \mathrm{~mm}$ ventral or lateral). (2) moderate osteochondrosis or spondylosis= moderate narrowing (maximum half of adjacent unaffected discs) or moderate osteophytes (3-5 $\mathrm{mm}$ ventral or lateral, $1-2 \mathrm{~mm}$ dorsal). 


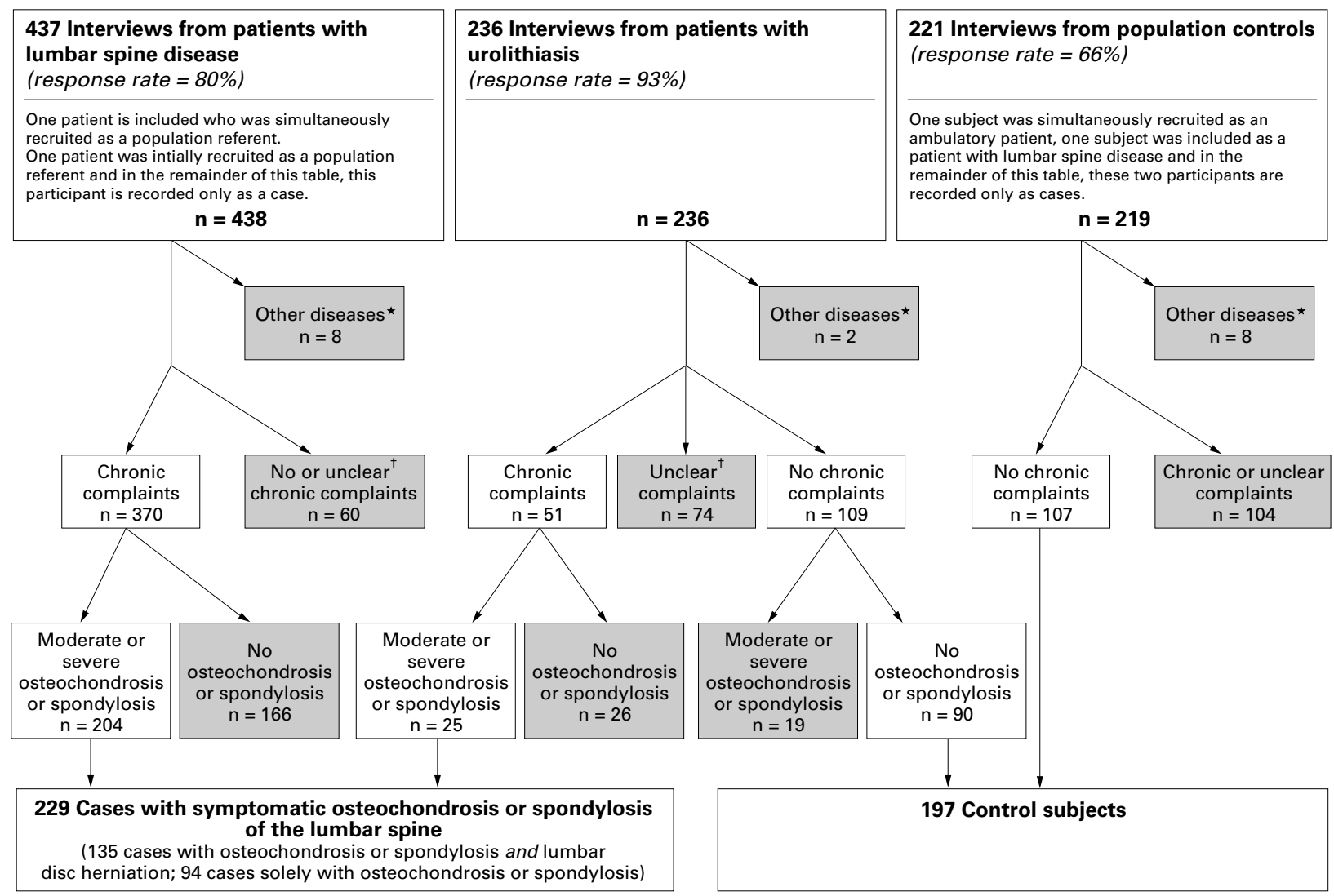

Figure 1 Flow chart of data collection, exclusion criteria (excluded subjects are marked grey), and resulting groups of cases with osteochondrosis or spondylosis and referents. *Subjects with Bechterew's disease, fractures of the spine, malignancies involving the spine, or poliomyelitis. + Complaints $>7$ days in the past year, but never radiography because of low back pain; missing values about complaints; or complaints $\leqslant 7$ days in the past year and ever radiography because of low back pain (unless no pathological findings).

(3) Severe osteochondrosis or spondylosis= severe narrowing (more than half of adjacent unaffected discs) or severe osteophytes ( $>5$ $\mathrm{mm}$ ventral or lateral, $>2 \mathrm{~mm}$ dorsal).

To finally qualify as cases, patients had to have moderate or severe osteochondrosis or spondylosis ( 2 or 3 ) in at least one lumbar disc or lumbar vertebral body according to the assessment of the reference radiologist. To evaluate the reproducibility of the radiographic assessment, 92 assessments were repeated by two participating orthopaedic physicians. Agreement between raters was "fair to good" $(\kappa=0.55)$ for the radiographic diagnosis of a moderate to severe osteochondrosis or spondylosis.

From a $1 \%$ random sample of male Frankfurt residents aged 25 to 65 , drawn up by the Frankfurt population registration office, 147 people were randomly selected as control subjects. To achieve an age distribution comparable with that of the cases, a stratified sample overrepresenting people between 40 and 50 years and underrepresenting people below 35 years was drawn up. In the areas surrounding Frankfurt, we recruited 190 men as control subjects by random digit dialing. Of 337 population controls, 221 agreed to participate $(66 \%)$. Potential population controls were excluded from the study, if they had any of the lumbar spine diseases already mentioned or if they had chronic low back complaints (fig 1).
As a second control group, we selected all male patients admitted to hospital for treatment of urolithiasis by lithotrypsy in the Frankfurt University hospital during a defined time span. As urolithiasis is considered to be largely independent of occupation when climate is moderate, these patients constituted an unbiased control group. As patients undergoing lithotrypsy are routinely radiographically examined, this permitted an assessment for osteochondrosis and spondylosis at least in an anteroposterior view in this group of control subjects. Of 253 urological patients, 236 agreed to participate $(93 \%)$. Urological patients with any of the excluding diseases (Bechterew's disease, fractures of the spine, malignancies involving the spine, and poliomyelitis) were excluded from the study. Urological patients without chronic low back complaints were excluded from the control group if they had high grade osteochondrosis or spondylosis according to the reference radiologist's assessment (fig 1). If urological patients fulfilled all inclusion criteria as described for cases, they were included in the study as cases $(n=25$, fig 1).

Altogether, 229 male patients with radiographically confirmed osteochondrosis or spondylosis of the lumbar spine associated with chronic complaints were included in the analysis, 135 of whom had also had acute herniation of the lumbar disc (including 20 patients with disc herniations not verified by participating physicians). A total of 197 control subjects was 
included in the analysis- 107 population controls and 90 patients admitted to hospital for the treatment of urolithiasis.

RELATION BETWEEN OSTEOCHONDROSIS OR SPONDYLOSIS AND CHRONIC COMPLAINTS

To determine whether chronic symptoms as defined in the present study were actually related to osteochondrosis or spondylosis, we looked at the relation between findings in the routinely (before urolithiasis) conducted radiogram and low back complaints in urological patients. We compared radiological findings from urological patients who reported low back pain severe enough to have required radiological investigation for more than 7 days during the past year with those from urological patients reporting less or no low back pain. Defined thus, low back pain was found to be strongly associated with radiographic signs of osteochondrosis or spondylosis in the routinely conducted radiogram (odds ratio (OR) 5.4; $95 \%$ confidence interval (95\% CI) 2.2 to 13.0).

DATA COLLECTION

A detailed structured interview was developed to elicit information about worktime physical work load including lifting and carrying, working postures, whole body vibration; psychosocial work load; leisure activities; life events; and complaints. Questions were supplemented by illustrations where appropriate, for example, to explain modes of carrying and specific working postures. To avoid "questions that cannot be answered" 24 as far as possible, we did not base our questions on lifting or carrying on abstract categories of weight, frequency, and duration. Instead, we asked participants to describe specific objects that had been lifted or carried often, followed by questions considering weight, frequency, and duration of lifting or carrying as directly related to these objects. All subjects also answered a modified version of the Nordic questionnaire on musculoskeletal symptoms. ${ }^{25}$ The interviewers documented a complete (self reported) occupational history for each participant.

Interviews were conducted by two physicians and three medical students, who were intensively trained in standardised interview techniques and a non-differential approach to cases and controls. Participants were not informed of the hypotheses. They were asked to participate in a study on the theme "occupation and health". Two cases and 14 control subjects did not participate in the personal interview but filled in a self administrable short questionnaire.

EXPOSURE ASSESSMENT

The median latency period between the date of diagnosis reported by the physician and the data collection was 2 years. Therefore, for participants with an unknown date of diagnosis $(n=40)$, the point in time 2 years before data collection was taken as the date of diagnosis in cases, or, in control subjects, as the reference date. Generally, only exposures up to the date of first diagnosis or reference date, respectively, were considered for analysis.

Coding of the occupations was based on the German Federal Statistical Institute 1992 classification of occupations. Occupational groups were classified initially by an occupational physician (GE) for their exposure to carrying or lifting (low, medium, and high, table 1). Cumulative hours spent in working postures with extreme forward bending were calculated up to the year of diagnosis or reference year, respectively.

Cumulative exposure to lifting or carrying and trunk flexion was calculated in two different ways. Firstly, the squares of the weights lifted or carried at work were multiplied by the corresponding durations and summed; separate categories were formed for combined lifting or carrying and trunk flexion. Secondly, to create a combined value for lumbar spine exposure to lifting or carrying and for trunk flexion, the Mainz-Dortmund dose model (MDD), which is based on overproportional weighting of the lumbar disc compression force relative to the respective duration of lifting, ${ }^{26-28}$ was applied with modifications. An example of the calculation of the sum of exposures to the lumbar spine with the MDD is given in figure 2. For up to three different objects or groups of objects, on the basis of their weight and average daily duration of carrying or lifting, forces to the lumbar spine at L5/S1 $\left(\mathrm{F}_{1}, \mathrm{~F}_{2}\right.$, and $\left.\mathrm{F}_{3}\right)$ were calculated using the formulas mentioned in figure 2. For working postures with extreme forward bending, the force on the lumbar spine at $\mathrm{L} 5 / \mathrm{S} 1$ was calculated as $\mathrm{F}=1700 \mathrm{~N}$. To calculate cumulative total work time exposure (before the diagnosis of lumbar spine disease), the sum doses for the individual work-years have to be totalled (fig 2). As an important difference to the original MDD model, we did not define minimum exposure limits for inclusion into the calculation of the cumulative exposure of the lumbar spine to lifting or carrying. The original MDD model neglects all exposures with a lumbar spine force below $3.2 \times 10^{3} \mathrm{~N}$ and with a daily exposure (considering actual instead of average daily lifting duration) below $5.5 \times 10^{3} \mathrm{Nh}$ (Newton $\times$ hours).

We elicited information about whole body vibration by showing the probands an illustrated table of possible vehicles. As whole body vibration is dependent on the terrain driven over, this was classified as smooth asphalt (factor 0 ), damaged asphalt (factor 1), cobbled streets (2), and rough terrain (3). The potential influence of whole body vibration was analysed in two ways: In the first approach, the cumulative duration of whole body vibration was calculated regardless of the type of terrain. In the second, the duration of whole body vibration was weighted for the type of terrain, using the indicated weighting factors $(0-3)$. Combined exposure to lifting or carrying, trunk flexion, and whole body vibration (unweighted duration, driving on smooth asphalt excluded) was assessed as suggested by Schäfer and Hartung, ${ }^{28}$ implementing our modified MDD approach as described. 


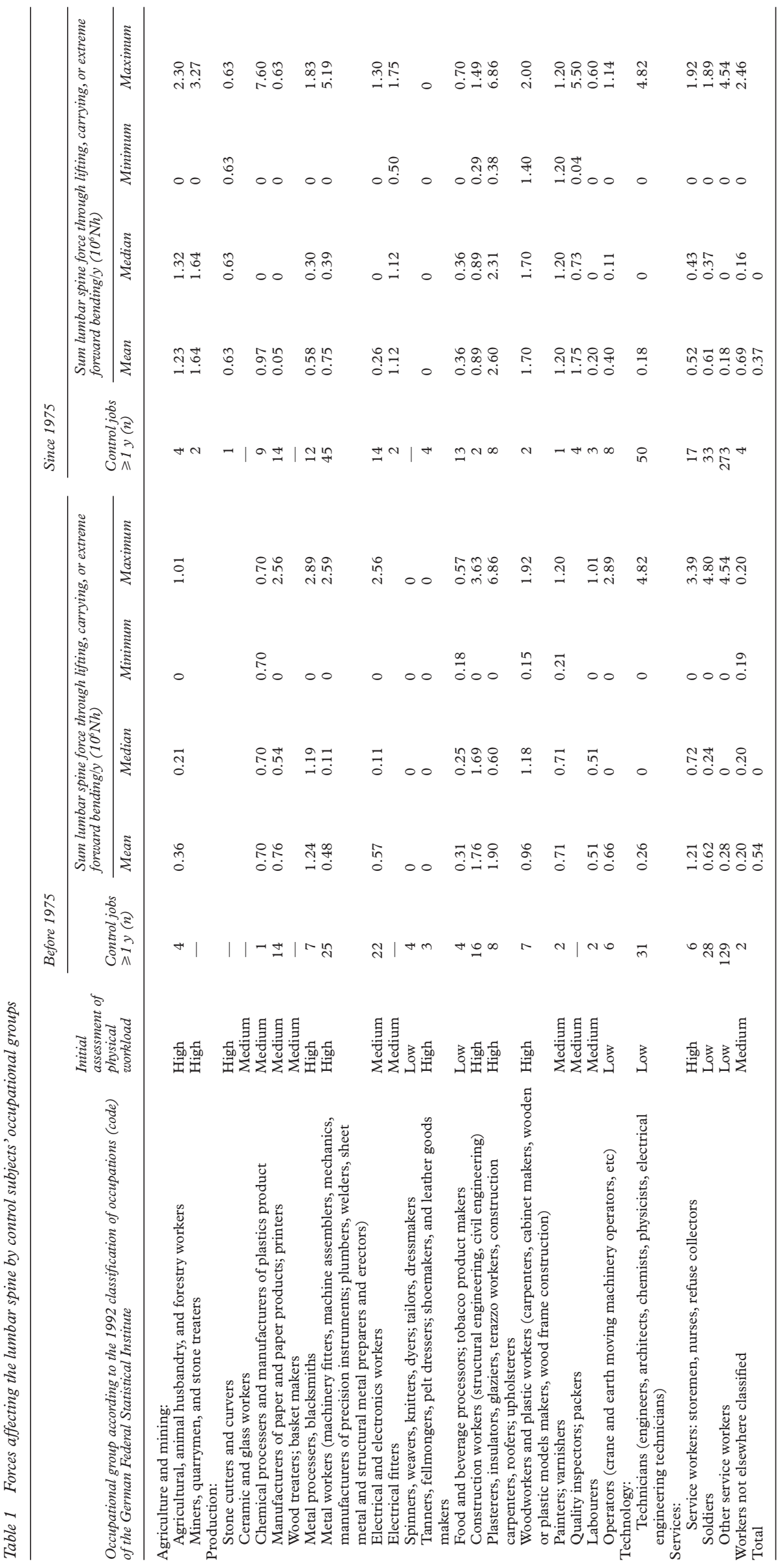

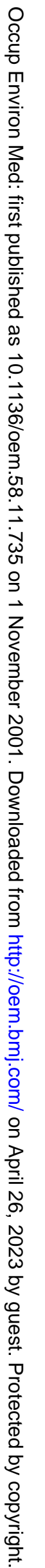


CONSTRUCTION OF AN INTERNAL JOB EXPOSURE MATRIX (JEM) ON THE BASIS OF THE CONTROL

SUBJECTS' ASSESSMENTS

As retrospective self assessment of carrying and lifting is open to differential recall bias, we constructed an internal job exposure matrix (JEM) based solely on the control subjects' assessments of physical work load. This was done separately for the time before 1975 and for the time after 1975. Every occupation held by control subjects was included in the JEM. For every occupational group, the mean and median of the individual work load assessments performed by the control subjects within the group were calculated. Based on this, the sum exposure to carrying or lifting and trunk flexion per year was calculated for each occupation (table 1, the internal job exposure matrix $(\mathrm{JEM}))$. Work time exposures of cases and control subjects were calculated on the basis of this internal JEM. One of 940 single occupations $(0.1 \%)$ held by control subjects and 10 of 1296 occupations $(0.8 \%)$ held by cases were unclassifiable with the JEM. For those unclassifiable occupations, calculation of exposure to carrying or lifting and trunk flexion was based on the mean or median exposure of all occupations held by control subjects. If, alternatively, the maximum or minimum exposure levels had been assigned to those unclassifiable occupations, this would not have substantially altered the results.

REPRODUCIBILITY OF OCCUPATIONAL EXPOSURES To evaluate the reproducibility of interview based past work loads, 47 interviews were repeated by an experienced interviewer who had not participated in the original data collection 1-2 years after the original data had been collected. We calculated $\kappa$ values comparing the categorised cumulative exposures derived from the first interview with the corresponding exposure categories derived from the retest. $\mathrm{k}$
Values exceeding 0.75 were regarded as excellent agreement beyond chance, values between 0.40 and 0.75 were rated fair to good agreement, and values below 0.40 represented poor agreement. Detailed results of this test-retest procedure will be published elsewhere. Briefly, agreement was excellent for occupational groups $(\kappa=0.77)$, fair to good for duration of sedentary work $(\kappa=0.68)$, sum of the forces on the lumbar spine (modified MDD model) through lifting or carrying or trunk flexion $(\kappa=0.67)$, cumulative lifting or carrying $(\kappa=0.58)$, and trunk flexion $(\kappa=0.43)$. Agreement was poor for total whole body vibration $(\kappa=0.39)$ and whole body vibration on uneven ground $(\kappa=0.18)$.

POTENTIAL CONFOUNDERS AND STATISTICS The mean (SD) age at diagnosis of lumbar spine disease in cases with osteochondrosis or spondylosis and lumbar disc herniation was 45.5 (10.4) years; in patients who had only osteochondrosis or spondylosis, the mean (SD) age at diagnosis was $48.4(10.1)$ years. The mean (SD) age of population controls 2 years before data collection (reference date) was 43.1 (10.3) years, and the mean (SD) age of hospital controls with urolithiasis on the reference date was 39.7 (10.6). The characteristics of the cases with symptomatic osteochondrosis or spondylosis of the lumbar spine and control subjects are given in table 2 .

Odds ratios (ORs) and 95\% confidence intervals (95\% CIs) were calculated by logistic regression analysis. To calculate tests for trend, the exposure scores were included as interval scaled variables in the logistic regression model. As age is known to be strongly associated with the occurrence of osteochondrosis or spondylosis, and as cases were on average older than control subjects, we decided to adjust for age. Age was entered into the logistic regression model in 5 year categories. Residential area of the subjects (region) was

Assumptions: One person working 220 days a year reported that he had carried object 1 (weighing $7.5 \mathrm{~kg}$ ) in front of the body for 6 hours on 110 days per year and object 2 (weighing $20 \mathrm{~kg}$ ) beside the body for 4 hours on 44 days in the year. The person reported no extreme forward bending. The total work time had been 5 years.

Calculation of lumbar spine forces:

\begin{tabular}{|c|c|c|c|c|c|c|c|c|}
\hline $\begin{array}{l}\text { Working } \\
\text { days/year }\end{array}$ & $\begin{array}{l}\text { Carrying } \\
\text { or lifting }\end{array}$ & Weight & $\begin{array}{l}\text { Days/ } \\
\text { year }\end{array}$ & $\begin{array}{l}\text { Duration/ } \\
\text { day (h) }\end{array}$ & $\begin{array}{l}\text { Average daily carrying } \\
\text { duration (h) }\end{array}$ & $\begin{array}{l}\text { Mode of carrying } \\
\text { or lifting }\end{array}$ & Formula & Lumbar spine force $F_{i}$ \\
\hline 220\{ & object 1 & $7.5 \mathrm{~kg}$ & 110 & 6 & $6 \star 110 / 220=3$ & in front of the body & 2 (see below) & $\mathrm{F}_{1}=1,000 \mathrm{~N}+85 \mathrm{~N} / \mathrm{kg} \star 7.5 \mathrm{~kg}=1637.5 \mathrm{~N}$ \\
\hline $\begin{array}{l}\text { Formula } \\
\text { Formula } \\
\text { Formula }\end{array}$ & \multicolumn{5}{|c|}{$\begin{array}{l}\text { 1: Lifting with both arms: } \\
\text { Carrying in front of or beside the body: } \\
\text { Carrying on both sides, on the shoulder, or on the back: } \\
\text { Extreme forward bending: }\end{array}$} & \multicolumn{3}{|c|}{$\begin{array}{l}F_{i}=1,800 \mathrm{~N}+75 \mathrm{~N} / \mathrm{kg}^{\star} \text { weight of object } \mathrm{i}(\mathrm{kg}) \\
\mathrm{F}_{\mathrm{i}}=1,000 \mathrm{~N}+85 \mathrm{~N} / \mathrm{kg}^{\star} \text { weight of object } \mathrm{i}(\mathrm{kg}) \\
\mathrm{F}_{\mathrm{i}}=1,000 \mathrm{~N}+60 \mathrm{~N} / \mathrm{kg}^{\star} \text { weight of object } \mathrm{i}(\mathrm{kg}) \\
\mathrm{F}_{\mathrm{i}}=1,700 \mathrm{~N}\end{array}$} \\
\hline
\end{tabular}

$\begin{aligned} \text { Sum dose for year } & =D A Y S \star \sqrt{8 h \star \sum_{i} F_{i}^{2} \star t_{i}} \quad \text { with } D A Y S=\text { working days per year; } t_{i}=\text { average daily lifting or carrying duration (h) } \\ & =220 \star \sqrt{8 h \star\left(1637.5^{2} N^{2} \star 3 h+2700^{2} N^{2} \star 0.8 h\right)}=2.32 \star 10^{6} \mathrm{Nh}\end{aligned}$

Calculation of cumulative exposure:

Cumulative exposure $=$ work-years (before the diagnosis of lumbar spine disease) ${ }^{\star}$ sum dose per year $=5 \star 2.32 \star 10^{6} \mathrm{Nh}=11.6 \star 10^{6} \mathrm{Nh}$

Result: $\quad$ In the hypothetical example, the cumulative lumbar spine exposure to lifting or carrying is $11.6 \star 10^{6} \mathrm{Nh}$.

Figure 2 Hypothetical example for the calculation of cumulative exposure to the lumbar spine with the modified Mainz-Dortmund dose model (MDD). 
considered to be a potential confounder because occupational exposures were suspected to differ between regions. All statistical analyses were therefore adjusted for age, region, nationality, and diseases potentially affecting lumbar discs (malposition of hip or pelvis, leg length discrepancy, scoliosis).

Furthermore, the following potential confounders were judged separately on their influence on the ORs for sum of the forces on the lumbar spine: body mass index; amount of smoking (pack years); whole body vibration; sedentary work; sporting activities such as soccer, handball, tennis, jogging, biking, body building, swimming; physically demanding leisure time activities (gardening, housebuilding, etc); severe life events (loss of proxies, loss of employment, etc); and psychosocial aspects of the work environment (psychic strain through contact with clients, time pressure at work, etc). None of the factors mentioned changed the OR for lumbar spine force by $20 \%$ or more in any exposure category, even if cases solely with osteochondrosis or spondylosis were analysed. Therefore, we retained none of these variables in the final regression model. Even when all variables mentioned were included in the model, for the highest category of sum of the forces of exposure on the lumbar spine the OR for symptomatic osteochondrosis or spondylosis with or without lumbar disc herniation changed by less than $10 \%$ compared with our final regression model.

Low education is itself likely to influence the choice of occupation towards physically demanding jobs. Additional adjustment for education might consequently lead to an underestimation of the relation between physical work load and lumbar spine disease. We therefore decided not to control for education. However, in our study further adjustment for education would have lowered the ORs slightly to moderately, but would not have fundamentally altered the results.

\section{Results}

SELF ESTIMATED PHYSICAL WORK LOAD

Patients with symptomatic osteochondrosis or spondylosis worked in occupations with high physical work load more often than control subjects. For symptomatic osteochondrosis or spondylosis with or without lumbar disc herniation, the OR for having worked in occupations with high physical work load was 3.2 (95\% CI 1.2 to 8.3 ) for a duration of less than 10 years and $6.2(95 \%$ CI 3.3 to 11.8$)$ for a duration of 10 years or more (table 3 , left column). The OR for working 10 years or more in occupations with moderate physical work load was 1.8 (95\% CI 1.0 to 3.2), which was of borderline significance. When only cases who had

Table 2 Characteristics of the cases with symptomatic osteochondrosis or spondylosis of the lumbar spine and control subjects

\begin{tabular}{|c|c|c|c|c|c|c|c|c|}
\hline \multirow[b]{2}{*}{ Characteristic } & \multicolumn{2}{|c|}{$\begin{array}{l}\text { Cases with osteochondrosis } \\
\text { or spondylosis and disc } \\
\text { herniation (including disc } \\
\text { herniations not verified by } \\
\text { participating physicians, } \\
n=20 \text { ) }\end{array}$} & \multicolumn{2}{|c|}{$\begin{array}{l}\text { Cases solely with } \\
\text { osteochondrosis or } \\
\text { spondylosis }\end{array}$} & \multicolumn{2}{|c|}{$\begin{array}{l}\text { Population controls } \\
\text { (including controls } \\
\text { recruited by random digit } \\
\text { dialing) }\end{array}$} & \multicolumn{2}{|c|}{$\begin{array}{l}\text { Controls admitted to } \\
\text { hospital for treatment of } \\
\text { urolithiasis }\end{array}$} \\
\hline & $n$ & $\%$ & $n$ & $\%$ & $n$ & $\%$ & $n$ & $\%$ \\
\hline \multicolumn{9}{|l|}{ Age at diagnosis $(\mathrm{y})$ : } \\
\hline$\leqslant 35$ & 32 & 23.7 & 15 & 16.0 & 31 & 29.0 & 38 & 42.2 \\
\hline$>35-40$ & 23 & 17.0 & 8 & 8.5 & 14 & 13.1 & 12 & 13.3 \\
\hline$>40-45$ & 21 & 15.6 & 8 & 8.5 & 9 & 8.4 & 15 & 16.7 \\
\hline$>45-50$ & 26 & 19.3 & 15 & 16.0 & 19 & 17.8 & 6 & 6.7 \\
\hline$>50-55$ & 17 & 12.6 & 16 & 17.0 & 22 & 20.6 & 11 & 12.2 \\
\hline$>55-60$ & 9 & 6.7 & 28 & 29.8 & 10 & 9.3 & 6 & 6.7 \\
\hline$>60$ & 7 & 5.2 & 4 & 4.3 & 2 & 1.9 & 2 & 2.2 \\
\hline Mean age $(y)$ & 45.5 & & 48.4 & & 43.1 & & 39.7 & \\
\hline \multicolumn{9}{|l|}{ Educational level: } \\
\hline Graduated from high school & 27 & 20.0 & 20 & 21.3 & 42 & 39.3 & 41 & 45.6 \\
\hline Secondary school level & 36 & 26.7 & 14 & 14.9 & 30 & 28.0 & 22 & 24.4 \\
\hline Elementary level, no graduation & 72 & 53.3 & 58 & 61.7 & 35 & 32.7 & 26 & 28.9 \\
\hline Unknown & - & - & 2 & 2.1 & - & - & 1 & 1.1 \\
\hline \multicolumn{9}{|l|}{ Region: } \\
\hline $\begin{array}{l}\text { Frankfurt, districts with } \geqslant 35 \% \text { blue collar } \\
\text { workers }\end{array}$ & 7 & 5.2 & 3 & 3.2 & 4 & 3.7 & 9 & 10.0 \\
\hline $\begin{array}{l}\text { Frankfurt, districts with } \geqslant 28-<35 \% \text { blue } \\
\text { collar workers }\end{array}$ & 22 & 16.3 & 12 & 12.8 & 22 & 20.6 & 8 & 8.9 \\
\hline $\begin{array}{l}\text { Frankfurt, districts with }<28 \% \text { blue collar } \\
\text { workers }\end{array}$ & 15 & 11.1 & 14 & 14.9 & 14 & 13.1 & 12 & 13.3 \\
\hline Hanau & 25 & 18.5 & 17 & 18.1 & 11 & 10.3 & 21 & 23.3 \\
\hline Offenbach & 14 & 10.4 & 25 & 26.6 & 26 & 24.3 & 2 & 2.2 \\
\hline Bad Homburg & 5 & 3.7 & 3 & 3.2 & 6 & 5.6 & 4 & 4.4 \\
\hline Darmstadt & 28 & 20.7 & 3 & 3.2 & 6 & 5.6 & 12 & 13.3 \\
\hline Offenbach county & 13 & 9.6 & 12 & 12.8 & 18 & 16.8 & 14 & 15.6 \\
\hline Others & 5 & 3.7 & 1 & 1.1 & - & - & 8 & 8.9 \\
\hline Unknown & 1 & 0.7 & 4 & 4.3 & - & - & - & - \\
\hline \multicolumn{9}{|l|}{ Nationality: } \\
\hline German & 105 & 77.8 & 67 & 71.3 & 84 & 78.5 & 62 & 68.9 \\
\hline Other & 20 & 14.8 & 6 & 6.4 & 12 & 11.2 & 22 & 24.4 \\
\hline Unknown & 10 & 7.4 & 21 & 22.3 & 11 & 10.3 & 6 & 6.7 \\
\hline \multicolumn{9}{|l|}{ Diseases potentially affecting lumbar discs: } \\
\hline None & 64 & 47.4 & 40 & 42.6 & 84 & 78.5 & 70 & 77.8 \\
\hline $\begin{array}{l}\text { Malposition of hip or pelvis, shortness of } \\
\text { the leg, etc. }\end{array}$ & 16 & 11.9 & 5 & 5.3 & 5 & 4.7 & 1 & 1.1 \\
\hline Scoliosis of lumbar spine & 40 & 29.6 & 29 & 30.9 & 12 & 11.2 & 12 & 13.3 \\
\hline $\begin{array}{l}\text { Malposition of hip or pelvis etc, and } \\
\text { scoliosis }\end{array}$ & 10 & 7.4 & 12 & 12.8 & 2 & 1.9 & 2 & 2.2 \\
\hline Unknown & 5 & 3.7 & 8 & 8.5 & 4 & 3.7 & 5 & 5.6 \\
\hline
\end{tabular}


never had lumbar disc herniation were included in the analysis (table 3, right column), only occupations with high physical work load were significantly associated with symptomatic osteochondrosis or spondylosis (OR 6.5; 95\% CI 2.7 to 16.1). The cumulative exposure of the lumbar spine to carrying or lifting gave a significant dose-response relation with disease

Table 3 Physical workload and osteochondrosis or spondylosis of the lumbar spine with chronic complaints

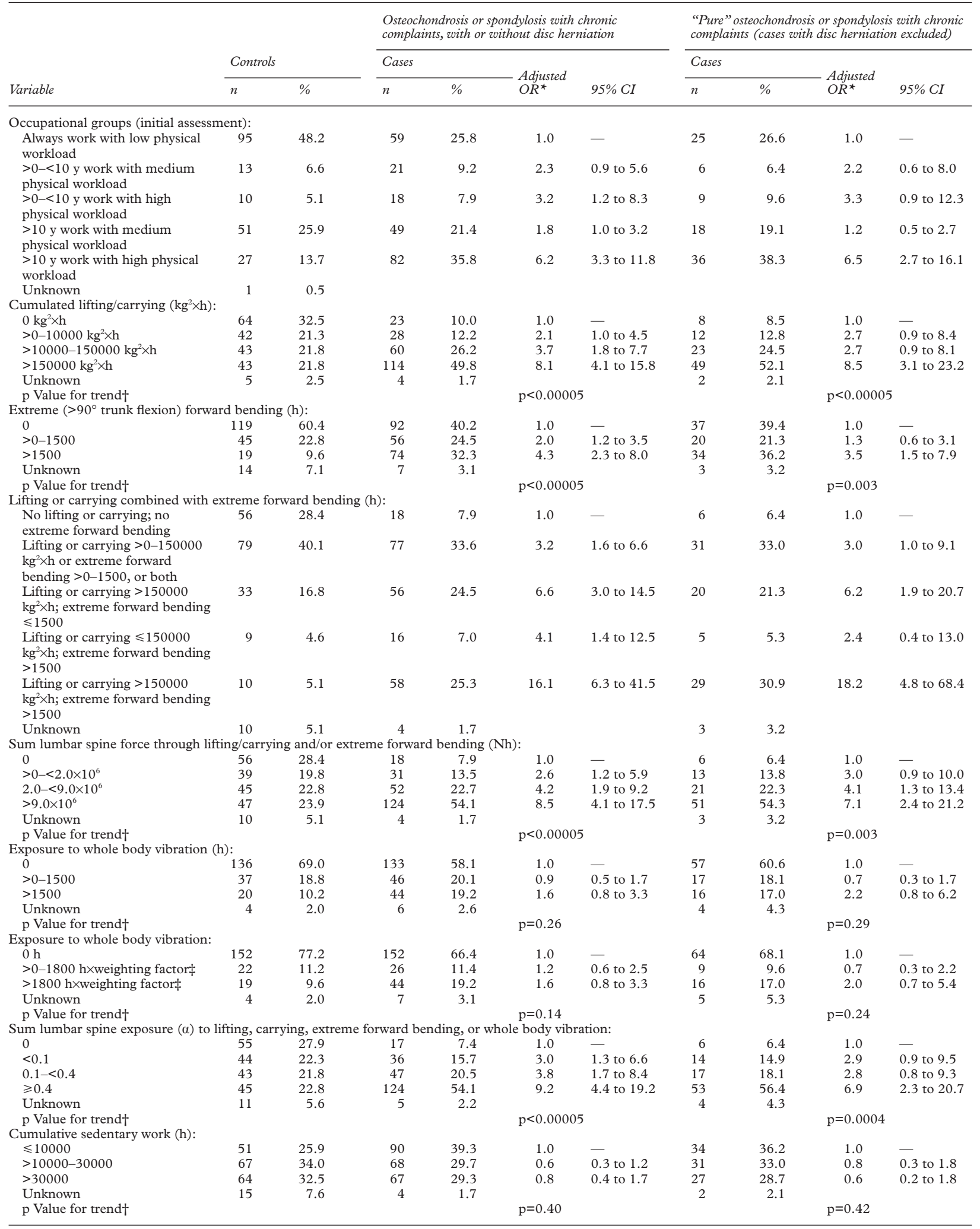

^Adjusted for age, region, nationality, and other diseases of the lumbar spine. Exposure to whole body vibration, sitting: additionally adjusted for sum lumbar spine force through lifting, carrying, or extreme forward bending.

†Exposure score included as a continuous variable in the logistic regression model.

†Weighting factor: 0 for smooth asphalt; 1 for damaged asphalt; 2 for cobbled streets; and 3 for rough terrain. 
Table 4 Physical work load according to internal $\mathcal{H E M}$ assessment and osteochondrosis or spondylosis of the lumbar spine

\begin{tabular}{|c|c|c|c|c|c|c|c|c|c|c|}
\hline \multirow[b]{3}{*}{ Variable } & \multirow{2}{*}{\multicolumn{2}{|c|}{ Referents }} & \multicolumn{4}{|c|}{$\begin{array}{l}\text { Osteochondrosis or spondylosis with chronic } \\
\text { complaints, with or without disc herniation }\end{array}$} & \multicolumn{4}{|c|}{$\begin{array}{l}\text { "Pure" osteochondrosis or spondylosis with chronic } \\
\text { complaints (cases with disc herniation excluded) }\end{array}$} \\
\hline & & & \multicolumn{2}{|c|}{ Cases } & \multirow{2}{*}{$\begin{array}{l}\text { Adjusted } \\
\text { OR }\end{array}$} & \multirow[b]{2}{*}{$95 \% C I$} & \multicolumn{2}{|c|}{ Cases } & \multirow{2}{*}{$\begin{array}{l}\text { Adjusted } \\
O R^{\star}\end{array}$} & \multirow[b]{2}{*}{$95 \% C I$} \\
\hline & $n$ & $\%$ & $n$ & $\%$ & & & $n$ & $\%$ & & \\
\hline \multicolumn{11}{|c|}{$\begin{array}{l}\text { Sum of forces to the lumbar spine through lifting, carrying, or extreme forward bending, calculated on the basis of the means of the individual workload } \\
\text { assessments performed by the referents within a given occupational group (Nh): }\end{array}$} \\
\hline$<3.0 \times 10^{6}$ & 46 & 23.4 & 21 & 9.2 & 1.0 & - & 9 & 9.6 & 1.0 & - \\
\hline $3.0-<6.0 \times 10^{6}$ & 53 & 26.9 & 38 & 16.6 & 1.6 & 0.7 to 3.5 & 11 & 11.7 & 0.7 & 0.2 to 2.5 \\
\hline $6.0-<10.5 \times 10^{6}$ & 50 & 25.4 & 55 & 24.0 & 2.6 & 1.2 to 5.7 & 25 & 26.6 & 2.2 & 0.8 to 6.4 \\
\hline$\geqslant 10.0 \times 10^{6}$ & 47 & 23.9 & 115 & 50.2 & 6.0 & 2.7 to 13.4 & 49 & 52.1 & 2.8 & 0.9 to 8.5 \\
\hline Unknown & 1 & 0.5 & & & & & & & & \\
\hline $\mathrm{p}$ Value for trend $\dagger$ & & & & & $\mathrm{p}<0.0000$ & & & & $\mathrm{p}=0.01$ & \\
\hline \multicolumn{11}{|c|}{$\begin{array}{l}\text { Sum of forces to the lumbar spine through lifting, carrying, or extreme forward bending, calculated on the basis of the medians of the individual workload } \\
\text { assessments performed by the referents within a given occupational group }(\mathrm{Nh}) \text { : }\end{array}$} \\
\hline 0 & 64 & 32.5 & 42 & 18.3 & 1.0 & - & 17 & 18.1 & 1.0 & - \\
\hline$>0-<0.8 \times 10^{6}$ & 42 & 21.3 & 42 & 18.3 & 1.7 & 0.9 to 3.4 & 19 & 20.2 & 2.6 & 1.0 to 6.6 \\
\hline $0.8-<4.0 \times 10^{6}$ & 46 & 23.4 & 46 & 20.1 & 1.8 & 0.9 to 3.4 & 19 & 20.2 & 1.9 & 0.8 to 4.8 \\
\hline$\geqslant 4.0 \times 10^{6}$ & 44 & 22.3 & 99 & 43.2 & 3.7 & 2.0 to 6.8 & 39 & 41.5 & 2.9 & 1.2 to 6.9 \\
\hline Unknown & 1 & 0.5 & & & & & & & & \\
\hline $\mathrm{p}$ Value for trend $\dagger$ & & & & & $\mathrm{p}=0.0001$ & & & & $\mathrm{p}=0.04$ & \\
\hline
\end{tabular}

^Adjusted for age, region, nationality, and other diseases of the lumbar spine.

†Exposure score included as a continous variable in the logistic regression model.

(table 3, left column), with an OR of 8.1 (95\% CI 4.1 to 15.8 ) in the highest category $\left(>150000 \mathrm{~kg}^{2} \times \mathrm{h}\right)$. When cases with lumbar disc herniation were excluded from the analysis (table 3, right column), the OR was 8.5 (95\% CI 3.1 to 23.2) in the highest exposure category. Working postures with extreme forward bending for up to 1500 hours (calculated over all working years) were also associated with the diagnosis of symptomatic osteochondrosis or spondylosis (OR 2.0; 95\% CI 1.2 to 3.5). The OR increased to 4.3 (95\% CI 2.3 to 8.0) for subjects who had worked more than 1500 hours with extreme forward bending. When cases with disc herniation were excluded (table 3, right column), the OR was 3.5 (95\% CI 1.5 to 7.9 ).

Combined exposure to lifting or carrying and to working postures with extreme forward bending gave an OR of 16.1 (95\% CI 6.3 to 41.5 ) in the highest exposure category (lifting or carrying more than $150000 \mathrm{~kg}^{2} \times \mathrm{h}$ and extreme forward bending for more than 1500 hours). When only cases who had never had lumbar disc herniation were included in the analysis, this OR was 18.2 (95\% CI 4.8 to 68.4). When the modified MDD model was applied to calculate the sum of exposure of the lumbar spine to lifting or carrying and to working postures with extreme forward bending, the OR for subjects with a sum of exposure $>9.0 \times 10^{6} \mathrm{Nh}$ was 8.5 (95\% CI 4.1 to 17.5 ) compared with subjects with a sum of exposure of $0 \mathrm{Nh}$. Restriction to cases without a history of lumbar disc herniation gave an OR of 7.1 (95\% CI 2.4 to 21.2 ).

High exposure to whole body vibration weighted for the type of terrain showed a nonsignificant OR of 1.6 (95\% CI 0.7 to 3.1 ). When cases were restricted to men without a history of lumbar disc herniation, the OR was 2.0 (95\% CI 0.7 to 5.4 ). The inclusion of whole body vibration into the sum of the exposure of the lumbar spine did not substantially alter the results in any case group. Adjusted for sum of the forces on the lumbar spine through lifting or carrying and extreme forward bending, no association could be found between the cumulative time spent doing sedentary work and the diagnosis of symptomatic osteochondrosis or spondylosis.

PHYSICAL WORK LOAD CLASSIFIED BY THE INTERNAL JEM

Assessment of physical work load based on the arithmetic means of the individual exposure assessments of the control subjects (the internal JEM approach) gave a significant association between sum of the exposures of the lumbar spine to lifting or carrying and trunk flexion (modified MDD model) and osteochondrosis or spondylosis (table 4, left column). The OR for subjects with a sum of exposure of 6.0 to $<10.0 \times 10^{6} \mathrm{Nh}$ versus subjects with a sum of exposure of up to $3.0 \times 10^{6} \mathrm{Nh}$ was $2.6(95 \%$ CI 1.2 to 5.7$)$; the OR for subjects with an exposure of more than $10.0 \times 10^{6} \mathrm{Nh}$ was 6.0 (95\% CI 2.7 to 13.4 ). When the median of the individual exposure assessments of the control subjects were used to estimate physical work load, the OR for subjects in the highest exposure category $\left(\geqslant 4.0 \times 10^{6} \mathrm{Nh}\right)$ was $3.7(95 \%$ CI 2.0 to 6.8$)$ compared with subjects with a sum of exposure of $0 \mathrm{Nh}$. When cases with a history of disc herniation were excluded from the analysis (table 4, right column), the OR for subjects in the highest exposure category based on the arithmetic means of exposure of the individual control subjects ( $\left.\geqslant 10.0 \times 10^{6} \mathrm{Nh}\right)$ was $2.8(95 \% \mathrm{CI}$ 0.9 to 8.5 ) compared with subjects in the lowest exposure category ( $p$ for trend=0.01); the OR for subjects in the highest exposure category based on the median of the exposure of individual control subjects was 2.9 (95\% CI 1.2 to 6.9 ) compared with subjects in the lowest exposure category ( $\mathrm{p}$ for trend=0.04).

\section{Discussion}

In this study, symptomatic osteochondrosis or spondylosis was found to be related to lifting or carrying of weights and working postures with extreme forward bending. Because of small numbers, we did not routinely differentiate between cases with narrowing of the disc space and with osteophyte formation. However, the 
data suggest that cumulative physical work load may possibly be a stronger risk factor for osteophytes than for narrowing of the disc space. Larger epidemiological studies are needed to elucidate further the effects of cumulative physical work load on specific outcomes.

DEFINITION OF CASES AND CONTROL SUBJECTS

Cases were recruited in orthopaedic practices and orthopaedic or neurosurgical clinics. Clinics as well as practices were not situated in working class areas. The clinics especially had wide catchment areas, with no indication of patient selection by socioeconomic criteria. Furthermore, to avoid bias because of regional differences in case-control ratio, we adjusted for the subjects' residential areas, distinguishing (in Frankfurt) between areas with low, medium, and high percentages of blue collar workers. Therefore, although a selection bias cannot be completely ruled out, it does not seem to be an adequate explanation for our results.

Due to lack of radiographic examination, the frequency of asymptomatic osteochondrosis or spondylosis is unknown among the population controls. Among urological patients who fulfilled the anamnestic criteria for control subjects, about $80 \%$ had no or only mild osteochondrosis or spondylosis in the routine anteroposterior radiograph. Although lack of further radiographic views limits our assessment of the specificity of a negative anamnestic diagnosis, this suggests that certainly some population controls may have had lumbar spine disease. This would result in a slight tendency to underestimate potential risk factors. As most control subjects were hospital based and were therefore (an advantage in the present study) radiologically examined for osteochondrosis or spondylosis, this effect was probably not large. When population controls were excluded from analysis, ORs for the sum of exposure to the lumbar spine increased slightly.

SELF REPORTED PHYSICAL WORK LOAD

Calculation of the sum of spinal exposure was based on self reported data on the weight of lifted or carried objects, the frequency and duration of lifting, and harmful working postures. Several studies have led to the conclusion that self reported exposure data cannot validly replace observations or direct measurements in the assessment of physical work load. ${ }^{29-33}$ Pope et $a l^{34}$ showed a satisfactory accuracy of the self reported estimates of frequency, duration, and amplitude of work postures, handling of manual materials, and repetitive movements. Undoubtedly, if cumulative exposures are hypothesised to play an aetiological role in diseases of the lumbar spine, prospective studies with direct measurements would be preferable, but would take a long time. Also, workplaces are tending to change towards decreasing physical work load over time, which diminishes potential risks and would therefore limit conclusions about the probability of an occupational cause of current lumbar spine disease. Therefore, despite their methodological limitations, in our opinion, self reported data remain an important and practicable tool in the assessment of physical work load.

One major potential limitation of self reported data concerns the possibility of differential recall bias. Patients with low back pain may overestimate their physical work load leading to an overestimation of potential risks. In a comparison of self reported physical work load against task analysis and observation $(n=36$ men in the forest industry), ViikariJuntura $e t a l^{35}$ found large differences especially in the assessments of trunk flexion between workers with severe low back pain and workers with no pain, suggesting differential recall. However, the authors could not exclude a true difference in levels of work between the symptomatic and non-symptomatic workers, as the actual levels of work load were unknown. In a study conducted by Wiktorin et al, ${ }^{36}$ musculoskeletal complaints seemed to cause differential bias in the self reported exposures to lifting, but not to postures. Burdorf and Laan ${ }^{31}$ actually found that workers with low back pain judged their duration of trunk flexion to be lower than workers without low back pain. In a study conducted by Köster et $a l,{ }^{37}$ subjects with low back disorders tended to show a better agreement in their assessment of retrospective exposures (25 year recall) than those without current symptoms, however, this differential recall did not substantially influence the estimation of relative risk. In a recently published study, questionnaire based information on past physical work loads (6 year recall) was compared with work site measurements performed 6 years before. ${ }^{38}$ Misclassification of exposure did not seem to be differential for musculoskeletal symptom status. In our opinion, that study points to the feasibility of retrospective assessment of previous physical work loads.

In the present study, we assessed the work load of cases as well as control subjects with a JEM based on the assessment of work load by control subjects. This approach avoids differential recall bias, but tends to introduce substantial misclassification by two mechanisms. Firstly, in this study, occupational groups were only roughly defined because of the small number of participants, which meant that people with large differences in individual physical work load were included within one occupational group. This would also tend to increase random error. Secondly, assuming that a causal relation exists between physical work load and symptomatic osteochondrosis or spondylosis, the JEM approach would in principle tend to underestimate the exposure of the cases, as even within an occupational category, people with the highest exposures would be expected to develop the disease more often and would therefore presumably be overrepresented. Both mechanisms would thus lead to an underestimation of risk by the internal JEM approach. Nevertheless, in the JEM approach we found a clear dose-response relation between physical work load and the diagnosis of osteochondrosis or spondylosis. These results suggest that although the presence of 
differential recall cannot be excluded, it was not an adequate explanation for the positive association between physical work load and symptomatic osteochondrosis or spondylosis.

PLAUSIBILITY OF RESULTS

The association found between carrying or lifting weights and awkward working postures with the diagnosis of symptomatic osteochondrosis or spondylosis accords with the published literature. ${ }^{6} 712$ 39-42 However, while the existence of this relation has been confirmed by all methodologically acceptable studies, a quantitative estimation of its strength is very difficult. Variation in previous results is wide mainly because of a wide range in the considered outcomes, occupations, and exposures. Also, study designs and statistical methods used were not uniform, and not all studies considered potential biases and confounders.

The results of the present study do not permit definitive conclusions about the relative importance of the weight of lifted or carried objects and the duration of carrying or lifting in the aetiology of symptomatic osteochondrosis or spondylosis. When exposure of the lumbar spine was calculated on the basis of the real weights instead of the squared weights, in the highest exposure category ORs were lower when cases with only osteochondrosis or spondylosis were considered (OR 5.9; 95\% CI 2.2 to 15.9 ); ORs were only slightly lower when all cases were considered (OR 7.1; 95\% CI 3.6 to 13.9 ).

Several experimental studies suggest that compressive forces can lead to structural changes in intervertebral discs-for example, decreased disc thickness - as well as to changes in intervertebral disc cell metabolism. ${ }^{43-46}$ Hutton et $a l^{45}$ were able to show an association between compressive force applied across the lumbar intervertebral discs of dogs over time in vivo and quantitative changes in proteoglycans and collagen in the disc. In keeping with the pathogenic concept of a chronic increase in intravertebral pressure being an important cause of lumbar spine disease, the present study is the first to use cumulative work time exposure as the independent variable. A subanalysis of all probands that were not exposed to lifting or carrying or extreme forward bending during 10 years before diagnosis ( 78 cases with osteochondrosis or spondylosis, 95 control subjects) had an OR of 5.1 (95\% CI 1.1 to 24.1) for subjects who had lifted or carried more than $150000 \mathrm{~kg}^{2} \times \mathrm{h}$ and who had worked more than 1500 hours with extreme forward bending. This suggests that past physical work plays an aetiological role in the development of symptomatic osteochondrosis or spondylosis.

In our study, whole body vibration was not found to be significantly associated with symptomatic osteochondrosis or spondylosis. However, as this exposure was much less common than, for example, exposure to heavy lifting, the power of this study to detect a potential relation between whole body vibration and symptomatic osteochondrosis or spondylosis is limited. Also, the self assessment of whole body vibration seems to be open to substantial misclassification. Therefore, negative results should be interpreted with caution. The lack of an association between sedentary work and symptomatic osteochondrosis or spondylosis seems to be biologically plausible in view of recent results of studies of intravertebral pressure. Although older pressure measurements conducted by Nachemson ${ }^{47}$ suggested that unsupported sitting augments intradiscal pressure, measurements recently conducted by Wilke et $a l^{48}$ showed a lower intradiscal pressure in the sitting compared with the standing position.

In conclusion, our results support a strong relation between total occupational physical work load and the diagnosis of symptomatic osteochondrosis or spondylosis. Calculation of a sum of exposure of the lumbar spine to lifting or carrying and to extreme forward bending seems to be a useful tool in risk assessment for epidemiological studies. This approach could also be useful for the assessment of whether symptoms and diagnostic findings might be attributable to occupational exposure at an individual level.

This work was supported by a grant from the Hesse Social Minstry and of the Hans-Böckler-Foundation. We thank Dr A Missalla, Professor Dr E Schmitt, Professor Dr R Lorenz, Professor Dr P Ulrich, and Dr F Leheta for their valuable contributions to the data collection.

1 Bernard B, ed. Musculoskeletal disorders (MSDs) and workplace factors. A critical review of epidemiologic evidence for work-related musculoskeletal disorders of the neck, upper extremity, and low back. Cincinnati, OH: NIOSH, 1997.

2 Burdorf A, Sorock G. Positive and negative evidence of risk factors for back disorders. Scand $\mathcal{f}$ Work Environ Health 1997;23:243-56.

3 Riihimäki H. Low-back pain, its origin and risk indicators. Scand $\mathcal{F}$ Work Environ Health 1991;17:81-90.

4 Kellgren JH, Lawrence JS. Rheumatism in miners. $\mathrm{Br} F$ Ind Med 1952;9:197-207.

Hult L. The Munkfors investigation. Acta Orthop Scand 1954;16(suppl)

6 Hult L. Cervical, dorsal, and lumbar spinal syndroms. Acta Orthop Scand 1954;17(suppl):1-102.

7 Lawrence JS. Disc degeneration: its frequency and relationLawrence JS. Disc degeneration: its frequency and re
ship to symptoms. Ann Rheum Dis 1969;28:121-38.

8 Torgerson WR, Dotter WE. Comparative roentgenographic Torgerson WR, Dotter WE. Comparative roentgenographic
study of the asymptomatic and symptomatic lumbar spine. study of the asymptomatic and symptom
7 Bone foint Surg Am 1976;58:840-53.

9 Wiikeri $M$, Nummi J, Riihimäki $H$, et al. Radiologically detectable lumbar disc degeneration in concrete reinforcement workers. Scand $\mathcal{F}$ Work Environ Health 1978;4(suppl 1):47-53.

10 Frymoyer JW, Newberg A, Pope MH, et al. Spine radiographs in patients with low-back pain. $\mathcal{F}$ Bone foint Surg 1984;66:1048-55.

11 Biering-Sorensen F, Rolsted Hansen F, Schroll M, et al. The relation of spinal $x$ ray to low-back pain and physical activity among 60-year-old men and women. Spine 1985;10: 445-51.

12 Riihimäki $\mathrm{H}$, Wickström $\mathrm{G}$, Hännninen $\mathrm{K}$, et al. Radiographically detectable degenerative lumbar changes as risk indicators of back pain. Scand $\mathcal{f}$ Work Environ Health 1989; 15:280-5.

13 Magora A, Schwartz A. Relation between the low back pain syndrome and $x$ ray findings: I. degenerative osteoarthritis. syndrome and $x$ ray findings: I. degen
$S$ cand $\mathcal{F}$ Rehabil Med $1976 ; 8: 115-25$.

14 Witt I, Westergaard A, Rosenklint A. A comparative analysis of $x$ ray findings of the lumbar spine in patients with and without lumbar pain. Spine 1984;9:298-300.

15 Freemont AJ, Peacock TE, Goupille P, et al. Nerve ingrowth into diseased intervertebral disc in chronic back pain. Lancet 1997;350:178-81.

6 Billenkamp G. Körperliche Belastungen und Spondylosis deformans. Fortschritte auf dem Gebiete der Röntgenstrvahlen und der Nuklear Medizin 1972;116:211-16.

17 Lawrence JS. Rheumatism in coalminers. Br f Ind Med 1955;12:249-61.

18 Mach J, Heitner H, Ziller R. Die Begutachtung der beruflichen Belastung für die Entstehung degenerativer Wirbelsäulenvernderungen. $Z$ ges Hygiene 1976;22:352-4.

19 Maintz G. Gibt es Schädigungen der Wirbelsäule durch Preßluftwerkszeugarbeit? Hefte Unfallheilk 1953;44:15462.

20 Sairanen E, Brüshaber L, Kaskinen M. Felling work, low back pain, and osteoarthritis. Scand $\mathcal{F}$ Work Environ Health 1981;7:18-30. 
21 Schröter G, Schlomka G. Über die Bedeutung der beruflichen Entstehung der degenerativen Gelenkleiden. Zeitschrift für die Gesamte inneve Medizin und ihre Grenzgebiete 1954;9:1031-7.

22 Ministerium für Gesundheitswesen. Arbeitsmedizinisch Tauglichkeits-und Überwachungsuntersuchungen. Berlin, DDR: Rechtsvorschriften und arbeitsmedizinische Untersuchungsmethoden, 1988

23 Gordon SJ, Yang KH, Mayer PJ, et al. Mechanism of disc rupture. A preliminary report. Spine 1991;16:450-6.

24 Burdorf A, van der Beek AJ. In musculoskeletal epidemiology are we asking the unanswerable in questionnaires on
physical load? [editorial]. Scand $\mathcal{F}$ Work Environ Health 1999;25:81-3.

25 Kuorinka I, Jonsson B, Kilbom A, et al. Standardised Nordic questionnaires for the analysis of musculoskeletal symptoms. Appl Ergonom 1987;18:233-7.

26 Jäger M, Luttmann A, Bolm-Audorff U, et al. MainzDortmunder Dosismodell (MDD) zur Beurteilung der Belastung der Lendenwirbelsäule durch Heben oder Tragen schwerer Lasten oder durch Tätigkeiten in extremer Rumpfbeugehaltung bei Verdacht auf Berufskrankheit Nr. 2108;Teil 1: Retrospektive Belastungsermitrankheit Nr. 2108; Teil 1: Retrospektive Belastungsermittlung für risikobehaftete Tätigkeit

27 Hartung E, Schäfer K, Jäger M, et al. Mainz-Dortmunder Dosismodell (MDD) zur Beurteilung der Belastung der Lendenwirbelsäule durch Heben oder Tragen schwere Lasten oder durch Tätigkeiten in extremer Rumpfbeugehaltung bei Verdacht auf Berufskrankheit Nr. 2108;Teil 2: Vorschlag zur Beurteilung der arbeitstechnischen Voraussetzungen im Berufskrankheiten-Feststellungsverfahren. Arbeitsmed Sozialmed Umweltmed 1999;34:112-2.

28 Schäfer K, Hartung E. Mainz-Dortmunder Dosismodell (MDD) zur Beurteilung der Belastung der Lendenwirbelsäule durch Heben oder Tragen schwerer Lasten oder durch Tätigkeiten in extremer Rumpfbeu Lasten oder durch Tatigk Heitu Verdacht auf Berufskrankheit Nr. 2108; Teil 3: Vorschlag zur Beurteilung der arbeitstechnischen Voraussetzungen im Berufskrankheiten-Feststellungsverfahren bei kombinierter Belastung mit Ganzkörper-Schwingungen. Arbeitsmed Sozialmed Umweltmed 1999;34:143-7.

29 Van der Beek A, Frings-Dresen MHW. Assessment of mechanical exposure in ergonomic epidemiology. Occup Environ Med 1998;55:291-9.

30 Van der Beek A, Braam ITJ, Douwes M, et al. The validity of a diary estimating tasks, activities, and postures of the trunk. Int Arch Occup Environ Health 1994;66:173-8.

31 Burdorf A, Laan J. Comparison of methods for the assessment of postural load on the back. Scand 7 Work Environ Health 1991;17:425-9.

32 Kumar S. Perception of posture of short duration in the spatial and temporal domains. Appl Ergonom 1993;24:345-
33 Wiktorin C, Selin K, Ekenvall L, et al. Evaluation of perceived and self reported manual forces exerted in occupational manual materials handling. Appl Ergonom 1996; 27:231-9.

34 Pope DP, Silman AJ, Cherry NM, et al. Validity of a self completed questionnaire measuring the physical demands of work. Scand $\mathcal{F}$ Work Environ Health 1998;24:376-85.

35 Viikari-Juntura E, Rauas S, Martikainen R, et al. Validity of self reported physical work load in epidemiologic studies on musculoskeletal disorders. Scand $\mathcal{f}$ Work Environ Health 1996;22:251-9.

36 Wiktorin C, Karlqvist L, Winkel J, et al. Validity of self-reported exposures to work postures and manual materials handling. Scand $\mathcal{F}$ Work Environ Health 1993;19: 208-14.

37 Köster M, Alfredsson L, Michélsen H, et al. Retrospective versus original information on physical and psychosocial exposure at work. Scand $\mathcal{F}$ Work Environ Health 1999;25: exposure 14

38 Torgén $\mathrm{M}$, Winkel J, Alfredsson L, et al. Evaluation of questionnaire-based information on previous physical work questionnaire-based information on previous physical

39 Wickström G, Nummi J, Nurminen M. Restriction and pain during forward bending in concrete reinforcement worke Scand $\mathcal{F}$ Work Environ Health 1978;4(suppl 1):29-38.

40 Wickström G, Niskanen T, Riihimäki H. Strain on the back in concrete reinforcement work. Br f Ind Med 1985;42: 233-9.

41 Elsner G, Nienhaus A, Beck W. Berufsbedingte degenerative Diskopathien im Lendenwirbelsäulenbereich. Soz Prävenyivmed 1997;42:144-54.

42 Riihimäki $H$. Back pain and heavy physical work: a comparative study of concrete reinforcement workers and maintenance house painters. Br f Ind Med 1985;42:22632.

43 Adams MA, McNally DS, Dolan P. "Stress" distributions inside intervertebral discs. The effects of age and degeneration. F Bone foint Surg Br 1996;78:965-72.

44 Handa $\mathrm{T}$, Ishihara $\mathrm{H}$, Oshima $\mathrm{H}$, et al. Effects of hydrostatic pressure on matrix synthesis and matrix metalloproteinase production in the human lumbar intervertebral disc. Spine production in the

45 Hutton WC, Toribatake Y, Elmer WA, et al. The effect of compressive force applied to the intervertebral disc in vivo. A study of proteoglycans and collagen. Spine 1998;23: 2524-37.

46 Iatridis JC, Mente PL, Stokes IAF, et al. Compressionnduced changes in intervertebral disc properties in a rat tail model. Spine 1999;24:996-1002.

47 Nachemson AL. Disc pressure measurements. Spine 1981; 6:93-7.

48 Wilke HJ, Neef $\mathrm{P}$, Caimi $\mathrm{M}$, et al. New in vivo measurements of pressures in the intervertebral disc in daily life. Spine 1999;24:755-62. 